\title{
Are Depression and Anger Two Sides of the Same Coin? Exploration through the ISTDP Model
}

\author{
Nimrat Singh \\ Practicing Clinical Psychologist, Heads Tangram - Tracking the Human Mind, Ahmedabad. \\ Corresponding author: Nimrat Singh \\ Email-nimrat@tangramhr.com
}

\begin{abstract}
Background and Objectives: The research paper explores the Intensive Short-term Dynamic Psychotherapy (ISTDP) model developed by Davanloo in treating depression of a 28 -year-old engineering graduate. Her presenting problem was low self-confidence and difficulty making decisions. She was caught in the crossfire between her boyfriend and her disapproving parents. She suffered somatic complaints of insomnia, low energy, lack of focus on her daily activities, and social withdrawal for the previous 6 months. She showed symptoms of depression and sought help to take control of her life. In 7 sessions, she showed marked improvement, her symptoms significantly reduced, and she was able to focus on her activities. Her dependency on her boyfriend decreased, and during this change she was able to experience anger and rage (bottled up against her parents since her childhood). She realized what her relationship pattern was: punishing herself by escaping into unhealthy relationships with men.

Results: The ISTDP model was useful in understanding the complex feelings toward her parents, especially her father. Her somatic symptoms reduced after the session discussed in the paper.

Conclusion: This model of addressing treatment resistant depression holds great promise for developing more effective case formulation and more effective treatment strategies. Evidence for its effectiveness with treatment resistant depression can be seen in several recent studies.
\end{abstract}

Keywords: Depression, ISTDP, anxiety and somatic complaints.

(Paper received $-31^{\text {st }}$ March 2018, Peer review completed - 20 ${ }^{\text {th }}$ April 2018)

(Accepted $-24^{\text {th }}$ April 2018)

\section{INTRODUCTION}

In Mourning and Melancholia, Freud [1] writes his famous description of the phenomenology of depression: "The distinguishing mental features of melancholia are profoundly painful dejection, abrogation of interest in the outside world, loss of the capacity to love, inhibition of all activity, and a lowering of self - regarding feelings that finds utterance in self - reproaches and self - reviling's and culminates in a delusional expectation of punishment". Using Freud's theory of structural conflict [2], Davanloo [3] grounds his formulation of the dynamics of depression in terms of the triangle of conflict: feelings, anxiety, and defense. The patient's forbidden aggressive feelings trigger anxiety, which in turn triggers the defense of turning of anger against the self (self-reproach, self-punishment), which creates the symptoms of depression, withdrawal, inhibition, and lowered self-regard.

Davanloo's technique of the "unlocking of the unconscious" [4-5] demonstrates that central to certain depressive disorders is the reliance on repression and internalization to deal with powerful aggressive impulses. Thus, Davanloo [3-5], conceptualizes the phenomenological hallmarks of depression (withdrawal, 
self-reproach, passivity, helplessness, and the sense of inferiority and inadequacy) as either defenses, or the result of defenses which ward off not only sadistic impulses but also associated painful feelings, such as guilt and grief.

Chronic reliance on depressive mechanisms creates ego-syntonic characteristic traits, such as passivity, helplessness, a tendency to assume a paralyzed, victimized stance, which lend to the individual's entire personality organization an air of defeat; he/she comes across as a beaten, crippled individual who gives every indication of being resourceless and depleted.

To work with the regressed, weakened ego organization characteristic of patients suffering from depressive disorders, Davanloo [6] developed a technique for restructuring the ego. These patients need help to identify, tolerate, and express their aggressive feelings without excessive anxiety and without turning the aggression upon themselves. In order to do this, they must be able to regulate their anxiety, develop their affect tolerance, and learn to see and let go of defenses which turn anger upon the self. Then, exploring feelings can be safely done without causing the use of self-attacking defenses that would otherwise trigger more depression.

The technique of restructuring aims to build the depressed person's affect tolerance to the level where the standard Short-Term Dynamic Psychotherapy techniques of inviting feelings and challenging defenses can be applied. It is for this reason that, prior to the application of challenge and pressure, the ego of the depressed patient must be restructured [3].

The goal of restructuring is the direct experiencing of the aggressive impulse. Implicit in that capacity is a psychic organization, Fosha (1988) characterized it by (1) an ego that can withstand the pressure of heightened impulse, (2) sadistic impulses which are not channeled against the self, and (3) sufficient energy available for therapeutic work [7].

As the therapist focuses on problem areas in the patient's life, she helps the patient observe, experience and let go of the defenses she uses to avoid feeling. Then the therapist helps the patient see the price she pays for using those defense (the symptoms). Then the patient can let go of the defense and face the feelings and issues she usually avoids. Through this repeated process, the patient is able to experience the feelings she formerly avoided and channel them into effective action rather than avoid them through defenses and suffer the resulting symptoms.

We see three primary systems of resistance that lead to depression:

1) Isolation of affect,

2) Repression, and

3) Projection.

Isolation of Affect: In isolation of affect, patients avoid the experience of mixed feelings in therapy by detaching from feelings and from people who trigger those feelings. Patients feel depressed because their use of detachment leaves them feeling lonely and isolated in relationships.

Repression: Patients who use repression cannot detach from their feelings. Instead, when they experience mixed feelings of love and rage, they protect other people by feeling love toward others and turning the rage back upon themselves. They feel depressed due to self-attack, weepiness, which covers their anger, character defense by which they treat themselves badly as others treated them, conversion, and somatization.

Projection: Patients who use the resistance system of projection cannot tolerate mixed feelings inside themselves, so they project those feelings outside onto others. "Oh, no I'm not angry with you; I'm afraid you are angry with me!" "I don't want to get closer to you; I'm afraid you are trying to get closer to me." "I don't have questions about my inner life. I'm afraid of the questions you want to ask!" These patients project their inner feelings and desires onto others, and then they fear other people as potential judges, critics, or attackers. As a result, they feel anxious, depressed, and hopeless, imagining they will never be loved (by these projections) [8].

Depression can be caused by detaching from mixed feelings, by loving the other and turning rage upon the self, or by avoiding mixed feelings by projecting feelings, especially anger, upon others. Thus, effective treatment of depression must target the cause---the patient's specific unconscious strategy for handling mixed 
feelings: 1) isolation of affect: helping the patient see and let go of defense, so she no longer detaches from her feelings and no longer detaches from the people who trigger those feelings; 2) repression: helping the patient see and let go defense, so she no longer turns rage upon herself and, instead, allows herself to feel mixed feelings toward others; and 3) projection: helping the patient bear mixed feelings inside herself without projecting them outside herself onto others.

Since most depressive disorders begin as anxiety disorders, attention to anxiety must be a central aspect of assessing treatment resistant depression. Anxiety, as is well known to any psychiatrist, is not a thought in the head, but a bio-physiological discharge pattern in the body mediated by the somatic and autonomic nervous systems [9]. Therefore, to assess anxiety we must pay close attention to physical symptoms in the body. These symptom patterns have distinct implications for the patient's capacity for affect tolerance, and they are correlated with specific patterns of resistance.

Once the amygdala is activated, messages are sent to the somatic and autonomic nervous systems, which activate the body and generate the physical symptoms we call anxiety. These symptoms of anxiety are correlated with specific patterns of activation of the somatic and autonomic nervous systems (ANS).

The somatic nervous system governs the striated muscles, known popularly as the voluntary muscles. When anxiety is discharged into these muscles we see the following symptoms: sighing, tension in the body (e.g., tension in the neck, feet, hands, and back), tension headaches, and clenching of the hands. Patients whose anxiety is discharged exclusively in the striated muscles have a very high tolerance for affect, and their resistance almost always takes the form of isolation of affect.

If the patient's anxiety tolerance is lower, anxiety shifts out of the striated muscles into the smooth muscles, i.e., out of the somatic nervous system into the parasympathetic branch of the ANS. Smooth muscles are in the linings of the digestive tract and blood vessels. Thus, when anxiety is discharged into the smooth muscles, we will see the following symptoms: stomach ache, nausea, diarrhoea, sudden urination, and migraine headaches. When these symptoms occur, anxiety is too high and requires immediate regulation. And when the patient's anxiety shifts into the parasympathetic nervous system, the resistance also shifts out of isolation of affect into repression.

If the patient's anxiety tolerance is even lower, anxiety continues to be discharged in the parasympathetic branch, but even more severely. With the continued drop in blood pressure, pulse, and breathing rate, Arnsten [10] proposed that we start to see hypo-perfusion of the prefrontal cortex, release of neurohormones to the prefrontal cortex and hippocampus [11-12], resulting in cognitive/perceptual disruption. Researchers say that now anxiety is so high that the patient's capacity to think and reflect are severely compromised. Signs of cognitive/perceptual disruption include: blurry vision, ringing in the ears, problems thinking or concentrating, delusions, hallucinations, projections with loss of reality testing. Anxiety at this level makes the patient unable to think, and the projections prevent any conscious alliance from forming.

"How much longer do your tears have to suffer out in the cold before you let them back in?"

"Don't worry mom. I know I should not let my feelings out. I will behave." [6-9]

\section{Treatment}

In the following vignette, the client $\mathrm{DB}$, the oldest daughter of 3 children, is an engineering graduate, aged 28 years, who has always protected her father from her rage and turned it inwards. As a result, she experienced depression and stayed in abusive and punitive relationships.

She becomes overly dependent on men who victimize her while she complies with their desires. This was her presenting problem. How can she either convince her parents that she wants to marry her boyfriend or convince him to breakup? Either way, she found it difficult to exercise her choice. Both ways she chose to be unhappy, as her source of happiness came from outside.

She grew up being very idealistic, compliant, and controlled by her mother. Her mother had a rough marriage in which she complied with all her husband's desires but then asked the patient to comply with hers. She wanted to tame her daughter from the start to avoid discord with men. The daughter, suffocated in this role with her mother, enacted it with her boyfriends. Having been her father's pet, she felt dethroned when her sister was born at age 4 . As a result, she felt in constant need of her father's attention. 
She completed her engineering degree but did not practice. After studying for her master's degree in the U.S., she returned, unable to decide what to study. This inability to commit showed up as well in four broken relationships and a broken engagement. She did not feel that she belonged and felt inadequate in all her relationships. Placing her desires onto others, she then believed that relationships were burdensome and draining. As a result, she took a passive position, waiting for others to make her decisions for her.

She came into therapy confused about the present relationship that started as a casual fling but became serious. The boy proposed marriage but she wanted to back out as it was just not in her 'plan' to get married to this boy. Totally confused, she found it difficult to make a decision. In therapy, when sharing her problems, she did so in a very clinical, detached manner, devoid of feelings. This was how she resisted emotional closeness in the session and remained detached from the therapist.

In subsequent sessions, she began to experience her anger toward both her parents. At first, due to her inability to recognize her anger, she felt low and depressed. She sought closeness with boyfriends, but then would feel trapped and would break off with them, only to feel depressed, missing their presence in her life. Rejecting her feelings and men, she became a recluse. In therapy, I helped her look at the anger she had covered up since childhood under the guise of compliance. As she began to face her anger toward her parents, relationships with them and her siblings improved.

Her use of compliance as a resistance against emotional closeness made it difficult to reach her true feelings. She needed to break away from her 'good girl' image and face her true feelings in therapy and toward her mother and father.

The following excerpts from a recent session shows her exploring feelings towards the father.

Client: "As I grew up, my dad became distant. There was no connection, or bond that is continuing."

Therapist: "How do you feel about your father's detachment?"

Client: "I thought I was comfortable so far, (denial) but now it makes me feel incomplete. Our relationship died the day my sister was born."

Therapist: "And, as your relation with dad slowly died, all your relationship slowly die."

Client: (Pause and silence). "I don't know what to do? I am confused whether I should focus on my relationship with my parents or my current boyfriend?" (Helplessness and confusion)

Therapist: "Is it your will to look at your feelings towards your father? What are the feelings towards your dad as you sit here and recall how he grew distant from you?"

Client: "I felt angry that I am not special any more. I have to accomplish and prove myself to get his attention. I achieved academically for him!"

Therapist: "Can we look at what feelings come up towards your father for abandoning you?"

Client: I feel angry, I feel it in my throat (sighing)." (Anxiety in striated muscles: dry mouth, sigh, tension in the chest).

Therapist: "Can we together look at what feelings come up that choke you and make you breathless?"

Client: "Now, I am angry with myself for...." (Anger turned inward - defense)

Therapist: "Notice how your anger turns inward. Yet there are feelings towards your father. And if you did not take the anger inside and allowed yourself to express anger towards him. How do you feel the anger rising towards him?"

Client: "I really want to scream."

Therapist: "How do you feel the anger in your body?"

Client: "Hands are restless. I want to punch up things and scream at him. I deserve my worthiness. I don't need to prove myself."

Therapist: "And can you see your anger building up? How do you experience the power of the anger within you?"

Client: "My hands and shoulders are really tensing up." (Striated muscle anxiety)

Therapist: "So as we keep taking a look at this anxiety, so we can understand this crippling force that has been sabotaging you where else in your body do you notice this anxiety? As you experience the anger in your body and you hold on to the intense feeling inside. (Anger building up.) Anger sabotages you, heaviness in your breath and your body. Would you like to feel powerful with your anger?"

Client: "Yes, but I hold back still when I feel angry. Am I trying to protect him?" (Defense) 
Therapist: "Only you would know whether you are doing so. Notice how you hide behind your passivity to protect him? Could that be the reason of feeling low and depressed? How about being kind to yourself? If you did not protect him and allowed the anger to come out from the body to the expression of expressing anger - How do you feel the anger towards him? (Her energy seemed to go down and she appeared passive and looked away) Notice how you look away and look away from your anger."

Client: "I feel weak, passive and confused. And allow the anger to push me." (Looks down, tension in the hands- straited muscles).

Therapist: "Holding on the power of anger. Can we look at how you experience your anger in your body?" (Shallow breath, choking sensation in the chest - striated muscles)

Client: "I really want to use my hands - push him and hit him scream at him. I want to blast him."

Therapist: "On a 10-point scale how angry you are now?"

Client: "8."

Therapist: "What do you want to do with the anger?"

Client: "I want to take it out. But don't know how to do so. (Helplessness) My chest and neck feel heavy."

Therapist: "Notice, you feel anger but push it back into your body and feel passive. How long would you want to keep the anger inside you? What are the feelings that come up towards me that does not allow you to experience it? You feel the anger in all your body. And then like a soda bottle you lose the fizz and get placid. The feelings come up towards me that make you put up the wall of helplessness and passivity. That keeps your anger under covers. The feelings?" (Pressure to feelings.)

Client: "Confused! If it's anger with me or with him?" (Helplessness)

Therapist: "Who would know? Do you notice how you turn the anger towards yourself? Is it your feeling or defense?"

Client: "My defense."

Therapist: "How is it helping you? That must be very frustrating to you. You would like my help today and you would like to take yourself seriously today, but this anxiety comes in sabotaging you at the very moment you want to look at your feeling. Right?"

Client: (Looks confused) "I have got comfortable with it. How will it help?" (Identification with resistance)

Therapist: "Yeah! That's your choice. Why feel powerful? Why respect your feelings? Why treat yourself well? You are joining him to get angry and disappointed with yourself. And he is right in getting angry with you. Why be kind to yourself, why listen to your body?"

The patient got mobilized-she straightened up bodily, felt powerful from within, and in five minutes she got into a portrayal.

Therapist: "Notice how you keep your eyes closed as you hit him."

(She looked up and in pain......More anger, more and more experience of anger).

Therapist: "If you did not hold back this compliant girl from expressing her anger, what would you do to him?" (She went into deeper portrayal and kept hitting continuously in her fantasy.)

Client: "Even if I didn't feel like studying I still did it. Just because I could be the star of your eyes.

It was an $\mathrm{f}^{*}$ burden on me."

(It went on for almost 10 minutes until her hands ached. But, she was overwhelmed with her anger and went on and on).

Therapist: "What would you do to him.... now? Pause. What's happening to him?"

Client: "He is dead. His face, skull and body are bleeding and bashed up. $\mathrm{He}$ is still breathing." (Thoughtfully)

(She started beating him again with both full strength in both her arms.)

Therapist: "Now what happening to him?"

Client: "Now he is dead."

Therapist: "What do you want to do with him now?"

Client: "I feel lighter in my chest and head. Though my hands ache."

Therapist: "What do you wish to do with him? How will you part from him?"

Client: "I want to burn him up. He deserves to go so, I have a break up with others as I had with my father."

Therapist: "What would you like to do with this intellectual understanding? What is happening physically in the body?" 
(Breath is shallow, gathering her breath)

Client: "I will punch him."

Therapist: "Where?"

Client: "His face."

(Grief. Then moved her hands very animatedly).

Client: "I have been protecting you from my own anger. But not anymore."(Grief). Ignoring me and just caring about my marks. You reduced me to a medal child. How I hate you. All love and attention got divided. I did not like it. I got scared.... Didn't understand."

(Closed her eyes and kept hitting him. Anger kept building up and getting released).

Client: "He is bleeding." (Body started going limp. After a brieflapse of silence).

Therapist: "Can you see that it's difficult to look up again and express your anger? Do you notice your body is going limp and passive? As if to say you don't give yourself more permission to get angry. Can you be kind to yourself? You have suffered enough."

Client: "I don't want to keep it within me anymore."

Therapist: "You want to be kind to yourself. Right?"

Client: "I want to hit him."

(And she went into another portrayal. She had released herself to a large extent. Slowly, she calmed down bodily. She tried reflecting on her relationship with her father in the present). Long silence

Client: "I say very little to my father - so he feels that everything is fine. I pretend to be calm and easy." (Soon guilt took over and she felt that he was not all bad. She realized that after the sister's birth she grew distant and did not take the liberties that her sister took.)

Client: "He was the same person and yet was so available to my sister and not to me."

Therapist: "What are the pros and cons of staying quiet?"

Client: "Cons are - I suffer. Pros - I am seen as a good girl. I have always yearned for his attention, and treated myself as unworthy if he doesn't endorse me. I hate him. I gave him all the power of my worthiness. Until it comes from there, it's still not good enough. I can't continue living like that. I need to cut my umbilical cord attached to my father. It's time I free myself." (She calmed down and came back into the present time).

Client: "Damn! I want to marry this boy I love, but my parents don't approve of him. And now I really don't know whether I want to marry him."

Therapist: "Hum! Can we look at the reason you are here? Thus, can you see any connection between your past and present relationships? Does it affect your relationships with other men?"

Client: "Yeah! I am always seeking their attention and approval. This makes me lose my dignity in the relationship. I feel that the boyfriend will abandon me and instead of the boyfriend abandoning me, I do so. That is the reason, I have lost out on many relationships. I understand clearly how my unfulfilled relationship with my father has led to many incomplete relationships with my boy friends. I seem to have a difficulty committing to a relationship. I have given my father reasons to be proud - and now that I am in love with a boy not of my caste, I am not good to be his daughter. I want him to accept my relationship. That's when I realized love is conditional. Now I am not 'sanskari' (cultured) and he has given up on me. He will not accept my choice. I feel free and now I don't need to protect him from my anger. I don't need to avoid him. A part of me wants to stand for myself and value myself and a part of me is angry with him." (She struggles between being the compliant and the confident girl).

Therapist: "What other thoughts come to your mind?"

Client: "Now I can be the real me with him. Like .... tell him how it is ... How I feel." I am not ecstatic but I can express and show I am angry... or I love it! I can choose my feelings. I never knew how to deal with him. I was defiant and defensive. I didn't want to work it through and tried pushing him and in turn ended up being so. And now, I am open to a new relationship. Now, I am not going to wear a mask of compliance any more. No more punishing myself. It feels really good taking anger out, than taking it in. I am still angry, but I am open to talking to him." 
(Her body was calm, eyes bright, yet she moved slowly. In this session, she felt deep rage four times toward her parents. Though sapped and fatigued, her clarity about her anger allowed her to free herself from her passive, depressed state.

\section{Outcomes}

The above case highlighted important principles for working with treating resistant depression:

1) The therapist identified the resistance system creating the symptoms.

2) Identified the pathway of anxiety regulation; (Straited, smooth, cognitive - perceptual pathways)

3) Regulated anxiety if it is not discharged into the striated muscles; and

4) Blocked, identified, and clarified defenses that caused depression immediately in order to prevent regression. She started showing signs of improvement after this session. Her symptoms markedly improved and she was able to open up with her father. Her focus on her work improved and she was at ease with herself.

\section{CONCLUSION}

This model of addressing treatment resistant depression holds great promise for developing more effective case formulation and more effective treatment strategies. Evidence for its effectiveness with treatment resistant depression can be seen in several recent studies [10].

The transcripts reveal that defenses, which cause depression, do not occur once or twice a session but constantly every minute. On an average 300 defenses per 60 minutes. Unless these defenses are addressed immediately, they create depression in session. Thus, an active strategy is necessary.

The therapist communicates the utmost care and respect for the patient as a human being, while maintaining an attitude of disrespect and intolerance for the defenses that cripple the patient's functioning and perpetuates her suffering. [11]

If defenses operate automatically in session without constant interruption by the therapist, the patient will continue to be held hostage by unconscious defenses she cannot see or respond to.

\section{REFERENCES}

1. Freud S. The paths to the formation of symptoms. Standard Edition. Hogarth Press; 1917.

2. Freud S. The libido theory. General psychological theory: Papers on metapsychology. Hogarth Press; 1923.

3. Davanloo H. Intensive short-term dynamic psychotherapy with highly resistant depressed patients. Part I. Restructuring ego's regressive defenses. Int J Short-Term Psychother 1987;2(2):99-132.

4. Davanloo H. Intensive short-term psychotherapy with highly resistant patients I. Handling resistance. Int J Sort Term Psychother 1986;1(2):107-33.

5. Davanloo H. Intensive short-term dynamic psychotherapy with highly resistant patients II. The course of an interview after the initial breakthrough. Int J Short Term Psychother 1986;1(4):239-55.

6. Davanloo H. Intensive short-term dynamic psychotherapy with highly resistant depressed patients. Part II. Royal road to the dynamic unconscious. Int J Short Term Psychother 1987;2(3):167-85.

7. Davanloo H. Short-term dynamic psychotherapy. New York: Jason Aronson; 1980.

8. Frederickson J. Overcoming Unconscious Forces in Treatment-Resistant Depression. Psychiatry 2016;79(2): 190-8.

9. Robertson M, Rushton PJ, Bartrum D, Ray R. Group-based interpersonal psychotherapy for posttraumatic stress disorder: theoretical and clinical aspects. Int J Group Psychother 2004;54(2):145-75.

10. Davanloo H. Basic principles and techniques in short-term dynamic psychotherapy. Spectrum Publishers; 1978.

11. Crits-Christoph PE, Barber JP. Handbook of short-term dynamic psychotherapy. Basic Books; 1991.

12. Sifneos PE. Short-term dynamic psychotherapy: Evaluation and technique. Springer Science \& Business Media; 2013.

$* * * * * * * * * * * * * * * * * * * * * * * * * * * * * * * * * * * *$

Acknowledgements - Nil; Conflict of Interest - Nil; Funding - Nil 